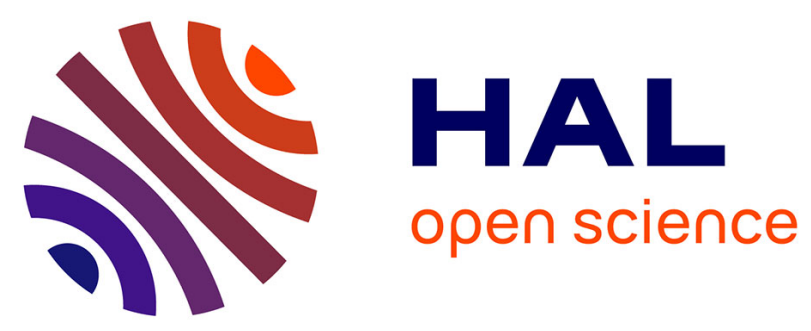

\title{
Desiccation and cracking behaviour of clay layer from slurry state under wetting-drying cycles
}

\author{
Chaosheng Tang, Yu-Jun Cui, Bin Shi, Anh Minh A.M. Tang, Chun Liu
}

\section{To cite this version:}

Chaosheng Tang, Yu-Jun Cui, Bin Shi, Anh Minh A.M. Tang, Chun Liu. Desiccation and cracking behaviour of clay layer from slurry state under wetting-drying cycles. Geoderma, 2011, 166, pp.111118. 10.1016/j.geoderma.2011.07.018 . hal-00629665

\section{HAL Id: hal-00629665 \\ https: / hal-enpc.archives-ouvertes.fr/hal-00629665}

Submitted on 6 Oct 2011

HAL is a multi-disciplinary open access archive for the deposit and dissemination of scientific research documents, whether they are published or not. The documents may come from teaching and research institutions in France or abroad, or from public or private research centers.
L'archive ouverte pluridisciplinaire HAL, est destinée au dépôt et à la diffusion de documents scientifiques de niveau recherche, publiés ou non, émanant des établissements d'enseignement et de recherche français ou étrangers, des laboratoires publics ou privés. 
Desiccation and cracking behaviour of clay layer from slurry state under wetting-drying cycles

4

Chao-Sheng Tang ${ }^{1 *}$, Yu-Jun Cui ${ }^{2}$, Bin Shi ${ }^{1}$, Anh-Minh Tang ${ }^{2}$, Chun Liu ${ }^{1}$

${ }^{1}$ School of Earth Sciences and Engineering, Nanjing University, 22 Hankou Road, Nanjing 210093, China

${ }^{2}$ Ecole des Ponts ParisTech, UR Navier/CERMES, 6 et 8, avenue Blaise Pascal, Cité Descartes, Champs-sur-Marne, 77455 Marne-la-Vallée CEDEX 2, France.

E-mail of the authors:

Chao-Sheng Tang: tangchaosheng@nju.edu.cn

Yu-Jun Cui: yujun.cui@enpc.fr

Bin Shi: shibin@nju.edu.cn

Anh-Minh Tang : tang@ cermes.enpc.fr

Chun Liu: oxtown@sina.com

* Corresponding author:

Chao-Sheng Tang

School of Earth Sciences and Engineering, Nanjing University

22 Hankou Road

Nanjing 210093, China

Tel: +86-25-83597888

Fax: +86-25-83596220

E-mail address: tangchaosheng@nju.edu.cn 


\section{Abstract}

2 Laboratory tests were conducted to investigate the effect of wetting-drying (W-D)

3 cycles on the initiation and evolution of cracks in clay layer. Four identical slurry

4 specimens were prepared and subjected to five subsequent W-D cycles. The water

5 evaporation, surface cracks evolution and structure evolution during the W-D cycles were monitored. The effect of W-D cycles on the geometric characteristics of crack patterns was analyzed by image processing. The results show that the desiccation and cracking behaviour was significantly affected by the applied W-D cycles: the measured cracking water content $\theta_{\mathrm{c}}$, surface crack ratio $R_{\mathrm{sc}}$ and final thickness $h_{\mathrm{f}}$ of the specimen increased significantly in the first three W-D cycles and then tended to reach equilibrium; the formed crack patterns after the second W-D cycle were more irregular than that after the first W-D cycle; the increase of surface cracks was accompanied by the decrease of pore volume shrinkage during drying. In addition, it was found that the applied W-D cycles resulted in significant rearrangement of specimen structure: the initially homogeneous and non-aggregated structure was converted to a clear aggregated-structure with obvious inter-aggregate pores after the second W-D cycle; the specimen volume generally increased with increasing cycles due to the aggregation and increased porosity. The image analysis results show that the geometric characteristics of crack pattern were significantly influenced by the W-D cycles, but this influence was reduced after the third cycle. This is consistent with the observations over the experiment, and indicates that the image processing can be used for quantitatively analyzing the W-D cycle dependence of clay desiccation cracking behaviour.

Keywords: wetting-drying cycle; clay layer; desiccation crack; aggregate formation; image processing; crack pattern 


\section{Introduction}

The formation of desiccation cracks on soil surface due to loss of water is a common natural phenomenon, and can significantly affect the soil performance in various geotechnical, agricultural and environmental applications. For example, a cracked soil is more compressible than an intact one at the same water content and the overall mechanical strength is weakened due to the presence of cracks (Morris et al., 1992). The size (width, length and depth), tortuosity, spatial distribution and connectivity of cracks govern the rate and the velocity at which solutes and microorganisms are transported in the soil, and thus control the dispersal of substances in soil (Horgan and Young, 2000). Most importantly, the soil hydraulic properties are directly controlled by the desiccation crack networks (Chertkov and Ravina, 1999; Chertkov, 2000). Many previous studies have indicated that the hydraulic conductivity of cracked soils is several orders of magnitude greater than that of intact soils (Boynton and Daniel, 1985; Albrecht and Benson, 2001). This issue is therefore a major concern in design and construction of low permeability structures as clay buffers and barriers for nuclear waste isolation, liners and covers for landfill, etc.

Over the past decades, a number of field studies and laboratory experiments have been undertaken to investigate the initiation and propagation of desiccation cracks in soils (Corte and Higashi 1960; Kleppe and Olson, 1985; Morris et al., 1992; Konrad and Ayad, 1997; Miller et al., 1998; Velde, 1999; Nahlawi and Kodikara, 2006; Tang et al., 2008; Tang et al., 2010). However, these investigations have been largely qualitative and most are limited in the description of desiccation cracking phenomena. More recently, techniques for quantifying the main features of the crack patterns have evolved from direct field measurement to more sophisticated analysis by image processing (Miller et al., 1998; Velde, 1999; Vogel et al., 2005). Image analysis has proved to be a powerful tool by which several geometric and morphologic parameters such as crack width, length, area, angle and their distribution characteristics can be determined effectively. In addition, some modelling and theoretical studies on desiccation cracking have also been conducted (Abu-Hejleh and Znidarčić, 1995; Ayad et al., 1997; Konrad and Ayad, 1997; Chertkov and Ravina, 1998; Chertkov, 2000; Chertkov, 2002; Deng and Shen, 2006; Péron, 2008; Péron et al., 2009a). However, as soil is a highly complex material, the desiccation cracking behavior is governed by a large number of factors including mineral composition, clay content, relative humidity, temperature, layer thickness, boundary conditions etc. (Fang, 1997; Albrecht and Benson, 2001; Nahlawi and Kodikara, 2006; Rodríguez et al., 2007; Tang et al., 2007; Tang et al., 2008; Tang et al., 2010). It is therefore difficult to propose a rational model to describe this complex phenomenon with a reasonable number of parameters. The essential mechanism of desiccation cracking is still not well understood today and the prediction of cracks initiation and the associated crack network propagation also faces several challenges.

It is recognised that the soil in-situ is subject to diurnal changes and seasonal rainy and sunny weather, and undergoes periodical wetting-drying (W-D) cycles. Several studies have been performed to investigate the effect of wetting and drying on soil 
physical properties (Rao et al., 2001; Alonso et al., 2005; Nowamooz et al., 2009, Tang et al. 2011). However, the relationship between W-D cycles and desiccation cracking behaviour is still not clearly understood. In this study, the effect of W-D cycles on cracking behaviour was investigated by subjecting a group of initially saturated clay layers to five W-D cycles. The initiation and evolution of cracks on the specimen surface during the cycles were monitored. The geometric characteristics of surface crack patterns are described and quantified through image processing and the mechanisms involved are discussed.

\section{Material and methods}

\section{Material}

The Romainville clay was used in this investigation. The physical properties are presented in Table 1. This clay is a lagoonal-marine deposit which is part of the Paris Basin Tertiary (Oligocene) formations. It is widely distributed over the eastern region of Paris, and has been considered responsible for the large amount of damages to buildings due to the swelling-shrinkage and cracking phenomenon. Various studies have been undertaken to analyse the hydro-mechanical behaviour of the clay under weather effects such as W-D cycles (Audiguier et al., 2007; Laribi et al., 2008; Geremew et al., 2009; Tang et al.,2009a; Tang et al., 2009b). However, little attention has been paid to the effect of W-D cycles on the desiccation cracking behaviour.

\section{Test methods}

The air-dried Romainville clay was crushed and sieved at $2 \mathrm{~mm}$. Saturated slurry specimens were prepared by mixing the crushed powder with distilled water at a water content of approximately $170 \%\left(\mathrm{~g} \mathrm{~g}^{-1}\right)$ (Note that all the given water contents of the tested specimens in the next sections is 'gravimetric' water content, unless otherwise specified). A desired quantity of slurry was then poured into glass cups (117 mm in diameter). To remove entrapped air bubbles in the slurry, these cups were placed on a vibration device for 5 minutes. Finally, the cups were sealed with plastic membrane and left for at least 3 days. The final settled layer thickness was about $10 \mathrm{~mm}$.

Four parallel specimens were prepared and dried at constant room temperature ( $25 \pm 1{ }^{\circ} \mathrm{C}, 50 \pm 5 \%$ of relative humidity) until the weight of specimen was stabilized, i.e., the first W-D cycle was completed. The subsequent wetting was started by pouring distilled water directly into the glass cups. During this wetting process, sufficient water was provided to ensure full submergence of the specimen and no mixing was applied. The glass cups were again sealed with plastic membrane to prevent water evaporation. After three days, the specimens were exposed to room conditions to be dried again. This procedure was repeated and finally a total of five W-D cycles was applied.

The schematic set-up used in this study is illustrated in Fig. 1. In order to measure the variation of water content during drying, the specimen was placed on a balance 
(with an accuracy of $0.01 \mathrm{~g}$ ) to monitor the weight. A digital camera was fixed above the specimens to capture the surface image during wetting and drying cycles in different time steps. Fig. 2 presents a typical crack pattern taken during the first drying path. With the application of image processing, the surface crack ratio $\left(R_{\mathrm{sc}}\right)$ or crack intensity factor CIF (Miller et al., 1998), defined as the ratio of the area of cracks to the total initial area of specimen, was determined to quantify the cracking extent during drying. At the end of each W-D cycle, other geometric parameters - the number of intersections per unit area $N_{\text {int }}$, number of crack segments per unit area $N_{\text {seg, }}$, mean crack length $L_{\mathrm{av}}$, mean crack width $W_{\mathrm{av}}$ and mean clod area $A_{\mathrm{av}}$ - were also determined from the final crack patterns. Note that the crack length was determined by calculating the length of the mid-axis of crack segment between two intersections. For this purpose, a skeletonising operation (Gonzalez and Woods, 2002) was initially performed by repeatedly removing pixels from the boundaries of cracks until they are reduced to single-pixel-wide skeletons. The crack width was sampled in orthogonal direction and the shortest distance between the crack boundaries was calculated. The clods are surrounded by cracks, and their areas are defined as the pixel number of the regions. All these parameters were obtained by applying the software CIAS which was developed by our research group. More details can be found in Liu et al. (2008) and Tang et al. (2008). Eight clods were selected from each specimen in the end of each drying period to determine their thickness using calliper, and the mean value is regarded as the final thickness of specimen layer.

In order to investigate the volume shrinkage behaviour of specimens during drying, four other identical specimens were prepared following the same procedure described above. During the first drying path, small clods were taken from the specimens in different time steps to determine their water contents $\theta$ and density $\rho$. The clod volume used for the density determination was measured by immersing it in a non-wetting hydrocarbon liquid. Then the void ratio $e$ and the corresponding degree of saturation $S_{\mathrm{r}}$ of specimens can be determined using the following equations:

$$
e=\frac{\rho_{s}(1+0.01 \theta)}{\rho}-1
$$

$$
S_{r}=\frac{\theta \rho_{s}}{e}
$$

where $\rho_{\mathrm{s}}$ is the density of the solid phase of the Romainville clay, equal to $2.79 \mathrm{Mg}$ $\mathrm{m}^{-3}$ (Table 1).

\section{Results}

\section{Evaporation, shrinkage and cracking process}

The measured water content $\theta$ at various times $t$ during the first drying path for the four separate specimens are shown in Fig. 3 (desiccation curve). Two distinct evaporation stages can be indentified: a constant evaporation stage during which water content decreases linearly with time; and a subsequent falling evaporation stage 
during which water loss slows down gradually until the residual water content of about $4.3 \%$ is reached.

The determined shrinkage curve ( $e$ versus $\theta$ ) is presented in Fig. 4, from which two transition points between linear and exponential phases can be determined - the air entry (AE) point and the shrinkage limit (SL) point (Stirk, 1954; Boivin et al., 2004; Groenevelt and Grant, 2004; Cornelis et al., 2006; Chertkov, 2007). The water contents at the point of AE and SL are approximately $18 \%$ and $12 \%$, respectively. After desiccation cracks appear on the surface of the specimen, the surface crack ratio $R_{\mathrm{sc}}$ at different water content $\theta$ was determined by image processing, and the result is also plotted in Fig. 4 as the cracking curve $\left(R_{\mathrm{sc}}\right.$ versus $\left.\theta\right)$. This indicates that the water content at the onset of cracking ranges from 38 to $43 \%$, which is much higher than the $\mathrm{AE}$ value. Therefore the specimens are still fully saturated as cracking occurs. During the initial stage, the $R_{\mathrm{sc}}$ increases rapidly with decreasing water content and decreasing pore volume. However, with further drying, the increment of $R_{\mathrm{sc}}$ slows down once the water content is close to AE point $(\theta=18 \%)$. After the $\operatorname{SL}(\theta=12 \%)$ is reached, the $R_{\mathrm{sc}}$ approaches a relative steady value of $14.6-15.8 \%$ for the four separate specimens.

\section{Cracking water content, final surface crack ratio and layer thickness}

During drying, when the first crack is observed on the specimen surface, the corresponding water content is herein defined as the cracking water content $\theta_{\mathrm{c}}$. Fig. 5 shows the determined $\theta_{\mathrm{c}}$ of the four specimens during each drying path. It indicates that $\theta_{\mathrm{c}}$ increases rapidly during the first three drying paths, and does not change significantly during the subsequent fourth and fifth drying paths. For instance, the mean value of $\theta_{c}$ of the four specimens during the first drying path is $40.5 \%$; increasing to $76.1 \%$ during the third drying path, whereas the mean value of $\theta_{\mathrm{c}}$ during the fifth drying path is $80.2 \%$, only $1.2 \%$ higher than the fourth drying path.

After each W-D cycle, the final surface crack ratio $R_{\mathrm{sc}}$ and the mean final thickness $h_{\mathrm{f}}$ were also determined and are presented in Fig. 6 and Fig. 7 respectively. Similar to $\theta_{\mathrm{c}}$, the final mean value of $R_{\mathrm{sc}}$ and $h_{\mathrm{f}}$ of the four specimens also increase quickly in the first three W-D cycles, while the increment rate slows down in the subsequent cycles.

\section{Geometric parameters of crack pattern}

Quantitative analysis of the crack pattern is important when studying clay cracking. Indeed, the geometric parameters are helpful in evaluating the hydro-mechanical properties of the clay-water system. They are also related to the variation of the stress-strain state and may provide a way to investigate the essential mechanisms of cracking. In addition, the crack propagation behavior and the geometric characteristics of the crack pattern reflect the material plasticity and mineral compositions. Perrier et al. (1995) indicated that if the real structure features of crack pattern can be determined, the soil response to wetting and drying can be predicted. 
Table 2 summarizes the mean values of the geometric parameters which were determined from the final crack patterns after each W-D cycle, the corresponding standard deviation (SD) are also presented. It is found that the mean values of all the parameters in the first three cycles are much more variable than that in the subsequent cycles. For $N_{\text {int }}$ and $N_{\text {seg }}$, they reach the maximum value after the second cycle and decrease after the third cycle. After that, $N_{\text {int }}$ and $N_{\text {seg }}$ increase slightly with further increase of W-D cycles. Moreover, the ratio of $N_{\text {seg }} / N_{\text {int }}$ is greater than 1.5 and less than 2 for all the cycles, indicating that, three or four crack segments sharing one intersection, is the dominant outline of the crack pattern. For $L_{\mathrm{av}}$, the maximum and the minimum values are $8.43 \mathrm{~mm}$ and $7.57 \mathrm{~mm}$ respectively after the first and second cycle. It is between 8.07 and $8.22 \mathrm{~mm}$ after the third cycle and no obvious trend can be observed. For $W_{\mathrm{av}}$, the minimum value is $1.01 \mathrm{~mm}$ that is observed after the first cycle; it reaches a maximum value at $1.86 \mathrm{~mm}$ after the third cycle and decreases slightly in the subsequent cycles. Based on the obtained values of $L_{\mathrm{av}}$ and $W_{\mathrm{av}}$, it can be deduced that most of the formed cracks in the first drying cycle are slim and threadlike. For $A_{\mathrm{av}}$, the maximum value is $1.18 \mathrm{~cm}^{2}$ observed after the first cycle. It generally decreases with increasing cycles and finally stabilizes at $0.65 \mathrm{~cm}^{2}$, indicating that the clods become smaller due to fragmentation. These results indicate that the geometric and morphologic characteristics of crack patterns are significantly influenced by W-D cycles, but the influence intensity declines after the third cycle. Moreover, the corresponding SD of the determined parameters generally decreases with increasing cycles, indicating that the initial densities, sizes or dimensions of the crack elements show significant variability but become more homogeneous under the effects of W-D cycles.

\section{Visual observations and discussion}

\section{Crack pattern and structure evolution after $W$-D cycles}

Fig. 8 presents the typical crack pattern after each W-D cycle. It indicates that the specimen surface was split to separate clods by the crack networks. After the first W-D cycle (Fig.8 (a)), the shapes of the clods are relatively regular and most of the clods are close to quadrangles or pentagons; the crack segments are smooth and generally perpendicular to each other. This is consistent with the observations of Vogel et al. (2005) and Peron et al. (2009b), and can be explained using the maximum stress release criterion and crack propagation criterion (Lachenbruch, 1962; Morris et al., 1992).

After the second W-D cycle (Fig. 8 (b)), the shapes of the separated clods are more irregular and the crack segments are more jagged than that observed in Fig. 8 (a). The second W-D cycle also caused dramatic aggregate formation from the initially non-aggregated structure. The formed clods were degraded significantly and a large number of inter-aggregate pores can be observed.

Figs. 8 (c), (d) and (e) indicate that the geometric and morphologic characteristics of the crack patterns are similar to each other after the third, fourth and fifth W-D 
cycle. This observation is consistent with the quantitative results of the geometric parameters in Table 2. In the tests of Yesiller et al. (2000) and Tang et al. (2008), most cracks after the second and third W-D cycles were found to be situated at the same locations as that after the first W-D cycle. However, this was not evident in this study when comparing Figs. 8 (a), (b) and (c). This can be attributed to the heterogeneous aggregated-structure formed during the wetting process. Many weak zones were created, which significantly control the start positions of cracks during the subsequent drying period (Yong and Warkentin, 1975).

Based on the results of surface crack ratio $R_{\mathrm{sc}}$ and layer thickness $h_{\mathrm{f}}$ shown in Figs. 6 and 7, the final total volume of the dried clods (without the cracks) as well as the increment of porosity after each W-D cycle can be calculated. It is found that, after the fifth cycle, the porosity of the clods increases by approximately $21 \%$. This is consistent with the findings of the previous studies on remolded and natural soils (Sartori et al., 1985; Pires et al., 2008), and can be explained by the progressive increase in pore volume and the average diameter of the pores with the increase of W-D cycles (Geremew et al., 2009).

\section{Crack pattern evolution and aggregate formation during wetting}

A time series of 6 images is shown in Fig. 9 to illustrate the evolution of surface cracks and aggregate formation process during the second wetting path. For reasons of simplicity and clarity, only the white marked area in Fig. 8 (a) is presented. Fig. 9 (a) shows the initial morphology of desiccation crack pattern taken from Fig. 8 (a). Figs. 9 (b) and (c) indicate that injecting water led to immediate collapse of the clods: the clods were broken down into several small aggregates. Meanwhile, some new micro-cracks induced by wetting appeared on the specimen's surface.

Notably, the collapse or destruction firstly occurred on the clods edges, especially on the corner positions (circled zones in Fig. 9 (b)). This is because rapid hydration firstly occurred at these less stable positions, and the previous cracks provided free spaces for clay swelling.

Upon further wetting, the original desiccation cracks tend to be increasingly narrow due to the filling of the exfoliated aggregates from the clods as well as the volume swelling of the clods. Fig. 9 (d) shows that the original desiccation cracks were fully closed after about 2.5 min wetting. However, there were more and more new micro-cracks induced by wetting. These new cracks are mainly resulted from the differential swelling pressures and the inner stresses during the wetting process of the clods. Fig. 9 (d) also shows that the specimen surface is not as flat and smooth as its initial state, but is 'heaved' along the trace of the original desiccation crack segments, as quadrangle marked in Figs. 9 (c)-(e). This is because the high swelling potential of the clay minerals was constrained so that the clods jostle against each other.

Comparison between Fig. 9 (e) and Fig. 9 (f) shows that the surface morphologies are similar to each other. The edges of the aggregates are clear and the wetting-induced new cracks can still be identified even after a long time (72 hours) has elapsed. However, in the test of Tang et al. (2008), the aggregates breakdown into 
individual fine particles and the new cracks were completely closed after a short wetting time of 2 hours. This can be attributed to the different clay fractions in the studied materials. For Romainville clay, the clay fraction is $79 \%$, which is $57 \%$ higher than Xiashu clayey soil used by Tang et al. (2008). The dispersion of aggregates was therefore prevented by the strong bonds between clay particles.

Pictures of the specimen subjected to the third wetting path are presented in Fig. 10. The observations are slightly different from the second wetting process (Fig. 9). After water was poured into the glass cup, clods degraded rapidly and some small aggregate plates floated on the water surface (Fig. 10 (a)). About 1.5 min later, the original desiccation cracks were fully closed (Fig. 10 (b)); after a period of $72 \mathrm{~h}$ wetting, all the clods were broken down and a large amount of individual aggregates can be observed (Fig. 10 (c)). However, no new micro-cracks or "jostle effects" were observed, as in the second wetting path (Fig. 9).

During the fourth and fifth wetting paths, no significant difference was observed as compared to the third wetting path, and as a result, no pictures are presented.

\section{Effect of W-D cycles on cracking water content}

Fig. 5 demonstrates that the W-D cycles result in significant increase in cracking water content $\theta_{c}$. Moreover, near $90 \%$ of the increase occurs in the first three cycles. Previous studies indicate that cracking occurs when the tensile stress induced by the developed suction exceeds the tensile strength of the specimen (Corte and Higashi, 1960; Morris et al., 1992; Miller et al., 1998; Péron et al., 2009b). The effects of W-D cycles on this cracking behaviour can be explained by considering the specimen fabric, as follows:

i) during W-D cycles, volume shrinkage and cracking would result in irreversible fabric changes, decrease of specimen integrity and increase of weak zones in specimen (Yong and Warkentin, 1975). As a result, the specimen tensile strength was reduced, promoting specimen cracking at a higher $\theta_{\mathrm{c}}$ upon the subsequent drying;

ii) the multiple W-D cycles gave rise to an increase in material heterogeneity as discussed in the above sections. For instance, after the first W-D cycle, the initial homogenous structure was changed to aggregated-structure during the subsequent W-D cycles (Fig. 8). Due to the non-uniform distribution characteristics of aggregate sizes and inter-aggregate pore sizes, the tensile stresses developed during subsequent drying cycles would be also non-uniform and can easily be concentrated at defects with lower tensile strength. Weinberger (1999) and Tang et al. (2008) have observed that cracks first initiated at surface defects, and emphasized that the surface defects can trigger or promote crack initiation due to shrinkage distortion of the surrounding medium and tensile stress concentration.

Note that because of the difficulty in drying tests, there has been no experimental data concerning the actual value of the local water content at the moment of crack initiation. The commonly measured water content in the laboratory is a mean value and can not completely reflect the moisture distribution characteristics in localised positions. To reduce the test error, the simplest way is to prepare an initially relatively 
homogenous specimen with a limited thickness - thus thin layer (10 mm thick) slurry specimens were prepared in this study. Generally, the physical, hydraulic and mechanical properties of the specimen vary permanently with moisture changes during drying. In order to better understand the intrinsic mechanism of desiccation cracking, future studies should also take into account some dynamic factors such as evaporation rate, suction development rate, volume shrinkage rate and tensile strength development rate, in addition to the critical water content $\theta_{\mathrm{c}}$.

\section{Equilibrium state during multiple W-D cycles}

Based on all the results shown in Figs. $5\left(\theta_{\mathrm{c}}\right), 6\left(R_{\mathrm{sc}}\right), 7\left(h_{\mathrm{f}}\right)$ and Table 2, it can be concluded that the cracking behaviour reached a relative equilibrium state after the specimens were subjected to the third cycle. This conclusion is also supported by the observations shown Fig. 8: no significant difference can be observed for the crack patterns after the third, fourth and fifth W-D cycle. Presumably the rearrangement of specimen fabric diminishes and finally ceases after certain a number of W-D cycles.

Previous studies on this subject also confirmed that there is an equilibrium state during multiple W-D cycles, but the corresponding numbers of cycles depend on material nature especially the clay fraction. Generally, clayey soils with high plasticity need more W-D cycles to reach the equilibrium state than silty or sandy soils (Al-Wahab and EI-Kedrah, 1995; Yesiller et al. 2000; Omidi et al., 1996).

\section{Conclusions}

Desiccation and cracking behaviour of clay layers from a slurry state upon five wetting-drying (W-D) cycles were investigated through laboratory experiments. The process of water evaporation, surface cracks evolution, structure evolution and volume shrinkage behaviour were monitored and have been discussed here. The geometric characteristics of crack pattern after each W-D cycle were quantitatively analyzed by image processing. The following conclusions can be drawn:

(1) during the first drying path, the water evaporation process is composed of two stages: a constant rate zone and a subsequent decreasing rate zone; the increase of surface crack ratio $R_{\mathrm{sc}}$ during drying was accompanied by progressive pore volume shrinkage, and the $R_{\mathrm{sc}}$ reached stabilization as the water content reached the shrinkage limit; the final crack pattern was dominated by polygonal clods and smooth crack networks;

(2) during the second wetting path, the poured water resulted in rapid collapse of clods, and the desiccation cracks formed in the previous drying path were quickly closed; meanwhile, a large number of new micro-cracks induced by wetting appeared on the specimen surface that divided the clods into smaller aggregates, and a typical aggregated-structure was developed and significantly intensified the specimen heterogeneity; moreover, the second wetting path led to significant rearrangement of clay particles and modification of the pore network; these processes are generally irreversible and drastically influence the desiccation cracking behaviour during the 
subsequent drying path;

(3) after the second drying path, since the specimen homogeneity decreased, the shapes of the clods were more irregular and the crack segments were more jagged than that observed after the first drying path; the clods showed clear aggregated-structure with a large amount of inter-aggregate pores; the bonds between the formed aggregates were broken quickly in the third wetting path and no new micro-cracks were induced;

(4) an equilibrium state can be reached after a certain numbers of W-D cycles; for the tested Romainville clay, it was observed that the rearrangement of specimen fabric or structure reached an apparent state of equilibrium after the third W-D cycle: before that, the measured cracking water content $\theta_{\mathrm{c}}$, final surface crack ratio $R_{\mathrm{sc}}$ and layer thickness $h_{\mathrm{f}}$ increased significantly with increasing cycles, but after, the effects of W-D cycles on the cracking behaviour and the cracking pattern became insignificant;

(5) image processing provided useful information on the geometric characteristics of crack patterns. The effect of W-D cycle on desiccation and cracking behaviour can therefore be quantitatively described through these specific parameters.

Generally, field soils are very complex and conditioned by a large number of variables. Cracking is a 3D phenomenon and the patterns are usually composed of irregular polygonal shapes. Quantification of a 3D crack pattern is a much more challenging task than the $2 \mathrm{D}$ process described in this investigation. However, it is believed that the findings of this laboratory experiment are helpful for better understanding the interrelationship between the sequence of seasonal processes and the evolution of soils or mud properties. In addition, as multiple W-D cycles can result in possible changes in clay structure and cracking behaviour, the hydraulic and mechanical properties of this type of materials must depend on the number of W-D cycles. Further attention should therefore be paid to the engineering fields where swelling clays are involved.

\section{Acknowledgements}

This work was supported by the National Natural Science of China (Grant No. 41072211), Research Fund for the Doctoral Program of Higher Education of China (Grant No. 20090091120037), State Key Program of National Natural Science of China (Grant No. 40730739) and the College Graduate Student Innovation Program of Jiangsu Province (CX09B_011Z). It was performed within the project ANR-RGCU «Analyse du Retrait-Gonflement et de ses Incidences sur les Constructions »- ARGIC. All the tests were performed at UR Navier/CERMES, Ecole des Ponts-ParisTech. Thanks to the two anonymous reviewers for their constructive comments that helped us to improve the manuscript.

\section{References}

Abu-Hejleh, A.N. and Znidarčić, D., 1995. Desiccation Theory for Soft Cohesive Soils. Journal of Geotechnical Engineering, 121(6): 493-502. 
Albrecht, B.A. and Benson, C.H., 2001. Effect of desiccation on compacted natural clays. Journal of Geotechnical and Geoenviromental Engineering, 127(1): 67-75.

Alonso, E.E., Romero, E., Hoffmann, C. and García-Escudero, E., 2005. Expansive bentonite-sand mixtures in cyclic con-trolled suction drying and wetting. Engineering Geology, 81: 213-226.

Al-Wahab, R.M. and El-Kedrah, M.A., 1995. Using fibers to reduce tension cracks and shrink/swell in compacted clay. In: Acar, Y.B., Daniel, D.E. (Eds.), Geoenvironment 2000. ASCE, New York, pp. 791-805.

Audiguier, M., Geremew, Z., Laribi, S. and Cojean, R., 2007. Caractérisation au laboratoire de la sensibilité au retrait-gonflement des sols argileux. Revue Française de Géotechnique, 120-121: 67-82.

Ayad, R., Konrad, J.M. and Soulié, M., 1997. Desiccation of a sensitive clay: application of the model CRACK. Canadian Geotechnical Journal, 34: 943-951.

Boynton, S.S. and Daniel, D.E., 1985. Hydraulic conductivity tests on compacted clay. ASCE Journal of Geotechnical Engineering, 111(4): 465-478.

Boivin. P., Garnier, P., Tessier, D., 2004. Relationship between clay content, clay type, and shrinkage properties of soil samples. Soil Sci. Soc. Am. J., 68: 1145-1153.

Chertkov, V.Y., 2000. Using surface cracks spacing to predict crack network geometry in swelling soils. Soil Science Society of America Journal, 64:1918-1921.

Chertkov, V.Y., 2002. Modelling cracking stages of saturated soils as they dry and shrink. European Journal of Soil Science, 53: 105-118.

Chertkov, V.Y., 2007. The reference shrinkage curve of clay soil. Theoretical and applied fracture mechanics, Theoretical and Applied Fracture mechanics, 48: 50-67.

Chertkov, V.Y. and Ravina, I., 1998. Modeling the crack network of swelling clay soils. Soil Science Society of America Journal, 62: 1162-1171.

Chertkov, V.Y. and Ravina, I., 1999. Tortuosity of crack networks in swelling clay soils. Soil Science Society of America Journal, 63:1523-1530.

Cornelis, W.M., Corlu, Y.J., Medina, H., Diaz, J., Hartmann, R., Van Meirvenne, M., Rui, M., 2006. Measuring and modeling the soil shrinkage characteristic curve. Geoderma 137: 179-191.

Corte, A. and Higashi, A., 1960. Experimental research on desiccation cracks in soil. Research report 66: U.S. Army Snow Ice and Permafrost Research Estabilishment, Wilmette, Illinois.

Deng, G. and Shen, Z.J., 2006. Numerical simulation of crack formation process in clays during drying and wetting. Geomechanics and Geoengineering, 1(1):27-41.

Fang, H.Y., 1997. Introduction to environmental geotechnology. CRC Press, Boca Raton. FL.

Geremew, Z., Audiguier, M. and Cojean, R., 2009. Analysis of the behaviour of a natural expansive soil under cyclic drying and wetting. Bulletin of Engineering Geology and the Environment, 68 (3): 421-436.

Gonzalez, R.C., Woods, R.E., 2002. Digital Image Processing Second Edition. Publishing House of Electronics Industry, Beijing.

Groenevelt, P.H., Grant, C.D., 2004. Analysis of soil shrinkage data. Soil and Tillage Research, 79: 71-77. 
Horgan, G.W. and Young, I.M., 2000. An empirical stochastic model for the geometry of two-demensional crack growth in soil (with discussion). Geodema, 96:263-276.

Kleppe, J.H. and Olson, R.E., 1985. Desiccation cracking of soil barriers. Hydraulic barriers in soil and rock, STP 874, ASTM, Philadelphia, pp. 263-275.

Konrad, J.M. and Ayad, R., 1997. An idealized framework for the analysis of cohesive soils undergoing desiccation. Canadian Geotechnical Journal, 34: 477-488.

Lachenbruch, A.H., 1962. Mechanics of thermal contraction cracks and ice-wedge polygons in permafrost. Geological Society of America, No 70. New York.

Laribi, S., Audiguier, M. and Cojean, R., 2008. Assessing shrink/swell properties of two argillaceous soils from the Paris Basin: a comparison of cation exchange determination methods. Bulletin of Engineering Geology and the Environment, 67(3): 415-424.

Liu, C., Wang, B.J., Shi, B. and Tang, C.S., 2008. The analysis method of Morphological parameters of rock and soil crack based on image processing and recognition. Chinese Journal of Geotechnical Engineering, 30(9): 1383-1388. (in Chinese, with English Abstract)

Miller, C.J., Mi, H. and Yesiller, N., 1998. Experimental analysis of desiccation crack propagation in clay liners. Journal of the American Water Resources Association, 34(3): 677-686.

Morris, P.H., Graham, J. and Williams, D.J., 1992. Cracking in drying soils. Canadian Geotechnical Journal, 29:263-277.

Nahlawi, H. and Kodikara, J., 2006. Laboratory experiments on desiccation cracking of thin soil layers. Geotechnical and Geological Engineering, 24(6):1641-1664.

Nowamooz, H., Mrad, M., Abdallah, A. and Masrouri, F., 2009. Experimental and numerical studies of the hydromechanical behaviour of a natural unsaturated swelling soil. Canadian Geotechnical Journal, 46(4): 393-410.

Omidi, G.H., Thomas, J.C. and Brown, K.W., 1996. Effect of desiccation cracking on the hydraulic conductivity of a compacted clay liner. Water Air and Soil Pollution, vol. 89. Kluwer Academic Publishers, Netherlands, pp. 91-103.

Péron, H., 2008. Desiccation cracking of soils. Ph.D. Thesis, Ecole Polytechnique Fédérale de Lausanne, Lausanne, Switzerland.

Péron, H., Delenne, J.Y., Laloui, L. and EI Youssoufi, M.S., 2009a. Discrete element modelling of drying shrinkage and cracking of soils. Computers and Geotechnics, 36: 61-69.

Péron, H., Herchel, T., Laloui, L., Hu, L.B., 2009b. Fundamentals of desiccation cracking of fine-grained soils: experimental characterization and mechanisms identification. Canadian Geotechnical Journal, 46: 1177-1201.

Perrier, E., Mullon, C., Rieu, M., 1995. Computer construction of fractal soil structures: simulation of their hydraulic and shrinkage properties. Water Resources Research, 31(12): 2927-2943.

Pires, L.F., Cooper, M., Cássaro, F.A.M., Reichardt, K., Bacchi, O.O.S. and Dias, N.M.P., 2008. Micromorphological analysis to characterize structure modifications of soil samples submitted to wetting and drying cycles. Catena, 72: 297-304.

Rao, S.M., Reddy, B.V.V. and Mutharam, M., 2001. The impact of cyclic wetting and 
drying on the swelling behavior of stabilized expansive soils. Engineering Geology, 60:223-233.

Rodríguez, R., Sánchez, M., Ledesma, A. and LIoret, A., 2007. Experimental and numerical analysis of desiccation of a mining waste. Canadian Geotechnical Journal, 44: 644-658.

Sartori, G., Ferrari, G.A. and Pagliai, M., 1985. Changes in soil porosity and surface shrinkage in a remolded, saline clay soil treated with compost. Soil Science, 139: 523-530.

Stirk, G.B., 1954. Some aspects of soil shrinkage and the effect of cracking upon water entry into the soil. Aust. J. Agric. Res. 5: 279-290.

Tang, C.S., Shi, B., Liu, C., Wang, B.J. and Gao, W., 2007. Developing law and morphological analysis of shrinkage cracks of clayey soil under different temperatures. Chinese Journal of Geotechnical Engineering, 27(5): 743-749. (in Chinese, with English Abstract)

Tang, C., Shi, B., Liu, C., Zhao, L. and Wang, B.J., 2008. Influencing factors of geometrical structure of surface shrinkage cracks in clayey soils. Engineering Geology, 101:204-217.

Tang, C.S., Cui, Y.J., Tang, A.M., Shi, B., 2010. Experimental evidence on the temperature dependence of desiccation cracking behavior of clayey soils. Engineering Geology, 114: 261-266.

Tang, A.M., Ta, A.N., Cui, Y.J. and Thiriat, J., 2009a. Development of a large-scale infiltration tank for determination of the hydraulic properties of expansive clays. Geotechnical Testing Journal, 32(5), doi: 10.1520/GTJ102187.

Tang, A.M., Cui, Y.J., Eslami, J. and Defossez, P., 2009b. Analysing the form of the confined uniaxial compression curve of various soils. Geoderma, 148: 282-290.

Tang A. M., Vu M. N., Cui Y. J., 2011. Effects of the maximum soil aggregates size and cyclic wetting-drying on the stiffness of a lime-treated clayey soil. Géotechnique 61 (5), 421-429.

Velde, B., 1999. Structure of surface cracks in soil and muds. Geoderma, 93: 101-112.

Vogel, H.J., Hoffmann, H., Roth, K., 2005. Studies of crack dynamics in clay soil I. Experimental methods, results, and morphological quantification. Geoderma, 125, 203-211.

Vogel, H.J., Hoffmann, H., Roth, K., 2005. Studies of crack dynamics in clay soil II. A physically based model for crack formation. Geoderma, 125: 213-223.

Weinberger, R., 1999. Initiation and growth of cracks during desiccation of stratified muddy sediments. Journal of Structural Geology, 21: 379-386.

Yesiller, N., Miller, C.J., Inci, G. and Yaldo, K., 2000. Desiccation and cracking behavior of three compacted landfill liner soils. Engineering Geology, 57:105-121.

Yong, R.N. and Warkentin, B.P., 1975. Soil properties and behavior. Elsevier, Amsterdam. 


\section{$1 \quad$ Tables}

2

3 Table 1 Physical properties of Romainville clay

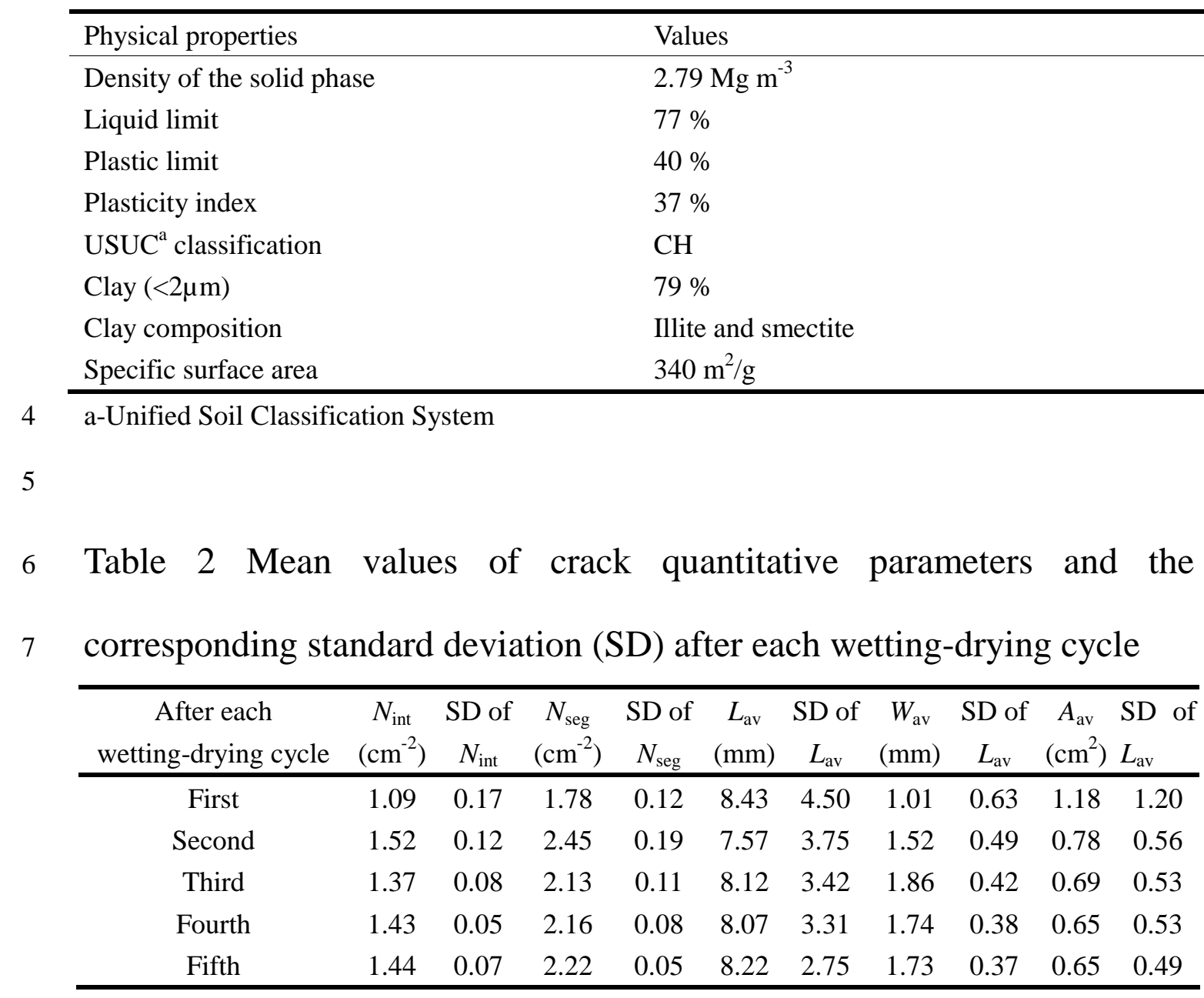




\section{$8 \quad$ Figure captions}

9 Fig. 1 Schematic drawing of set-up

10 Fig. 2 A typical desiccation crack pattern of specimen during the first

11 drying path

12 Fig. 3 Desiccation curves of the specimens during the first drying path

13 Fig. 4 Variation of surface crack ratio $R_{\mathrm{sc}}$ and void ratio $e$ with water

14 content $\theta$ during the first drying path

15 Fig. 5 Cracking water content $\theta_{\mathrm{c}}$ of the specimens during each drying path

16 Fig. 6 Surface crack ratio $R_{\mathrm{sc}}$ after each W-D cycle

17 Fig. 7 Mean thickness $h_{\mathrm{f}}$ of specimen layer after each W-D cycle

18 Fig. 8 Typical desiccation crack patterns after each W-D cycle (pictures

19 were taken from the same specimen)

20 Fig. 9 Evolution of crack pattern during the second wetting path

21 Fig. 10 Evolution of surface cracks during the third wetting path 


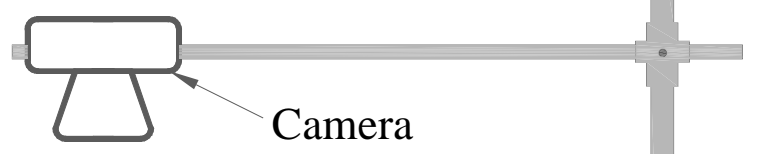

25

27

29 Fig. 2 A typical desiccation crack pattern of specimen during the first 30 drying path

Fig. 1 Schematic drawing of set-up

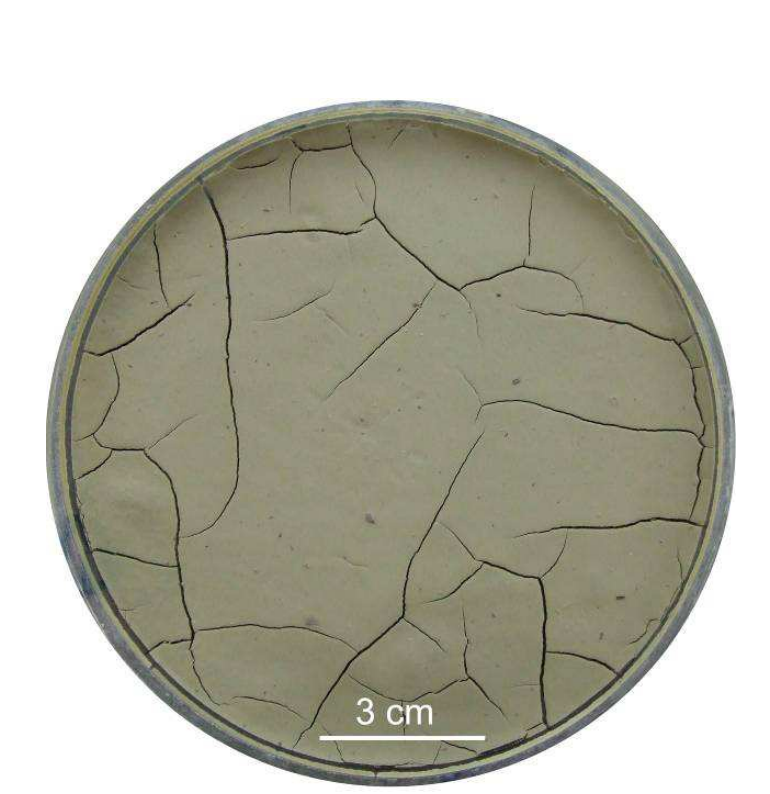

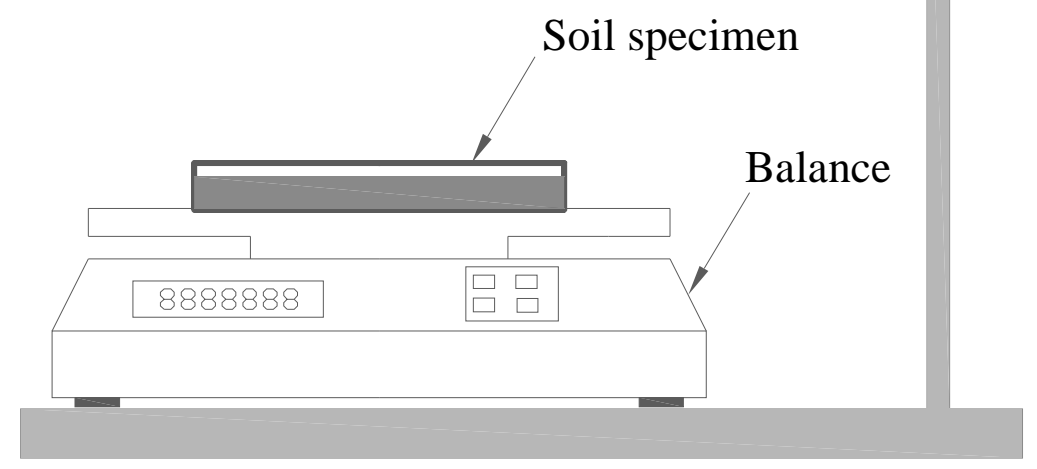




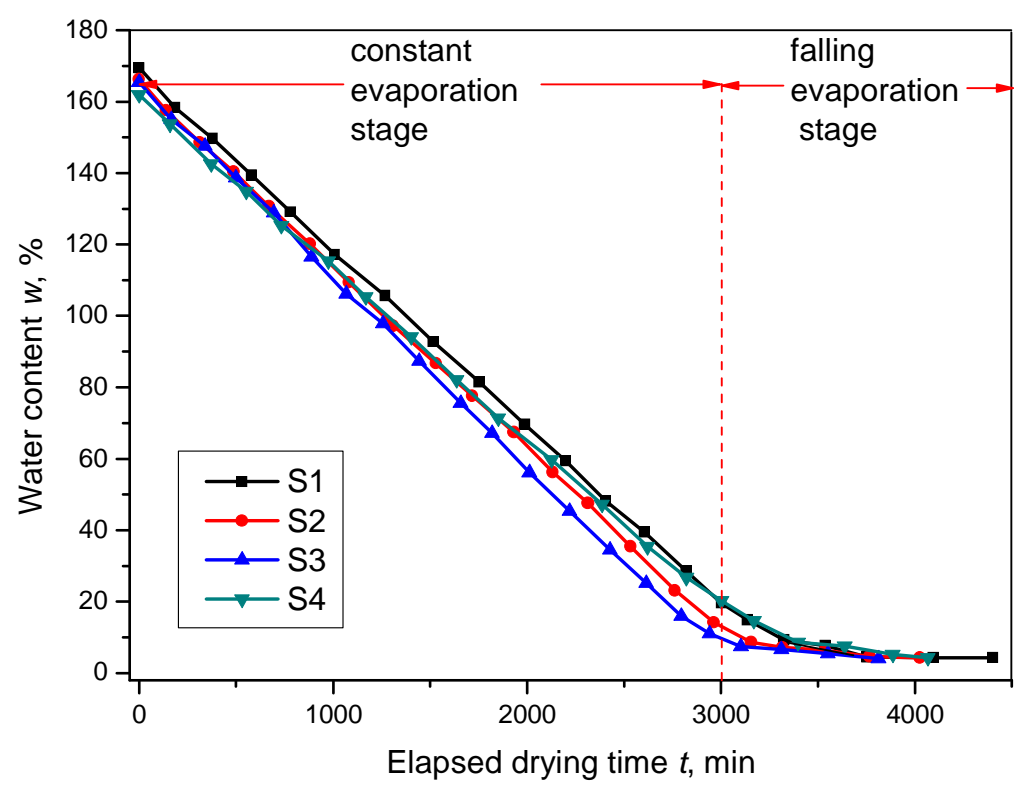

32 Fig. 3 Desiccation curves of the specimens during the first drying path

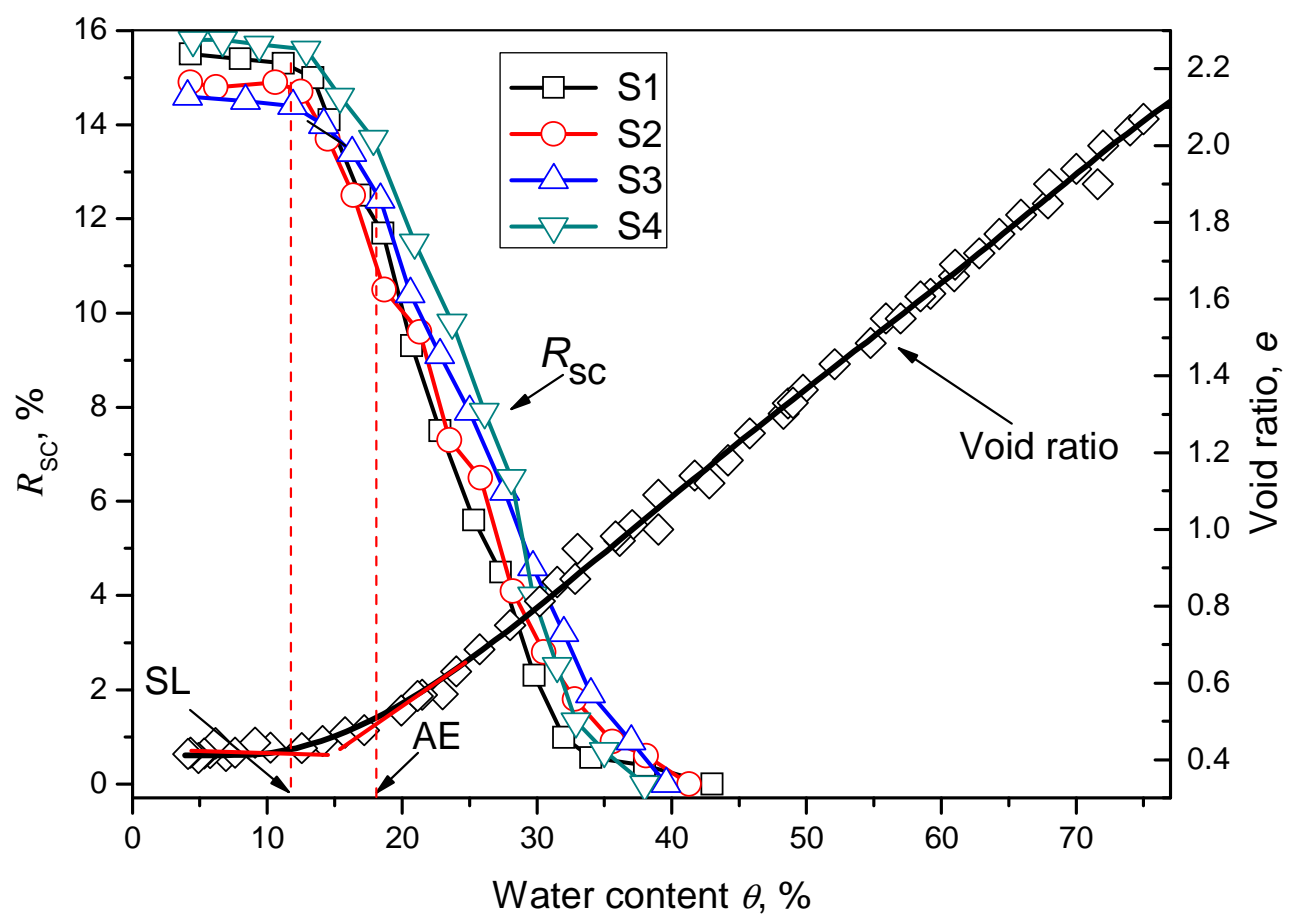

35 Fig. 4 Variation of surface crack ratio $R_{\mathrm{sc}}$ and void ratio $e$ with water content $\theta$ during the first drying path 


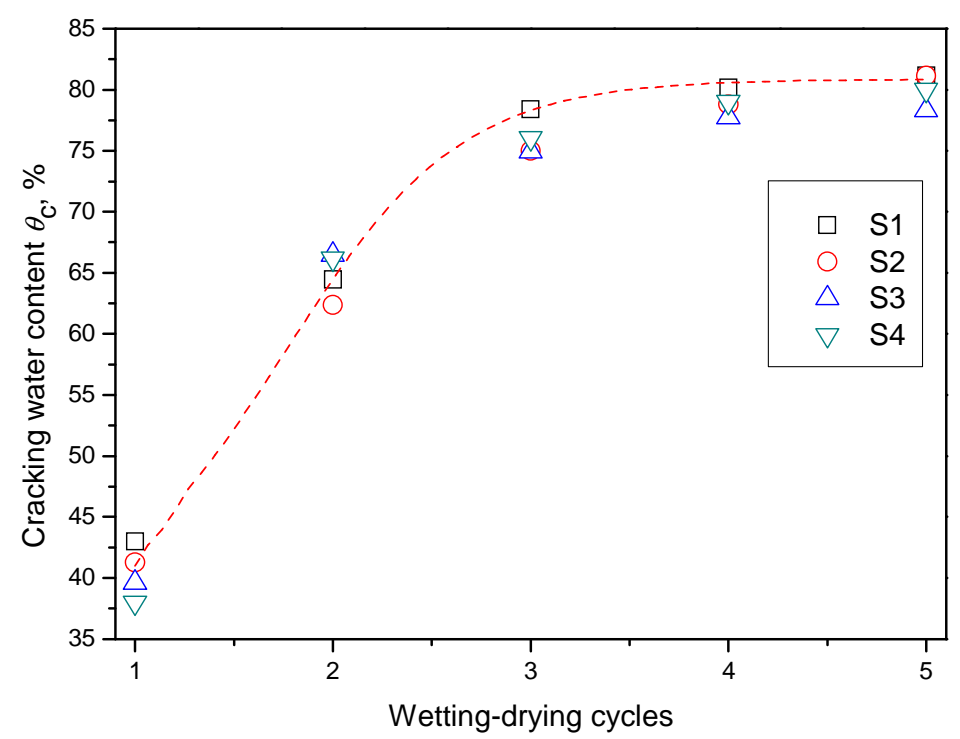

38

39 Fig. 5 Cracking water content $\theta_{c}$ of the specimens during each drying path

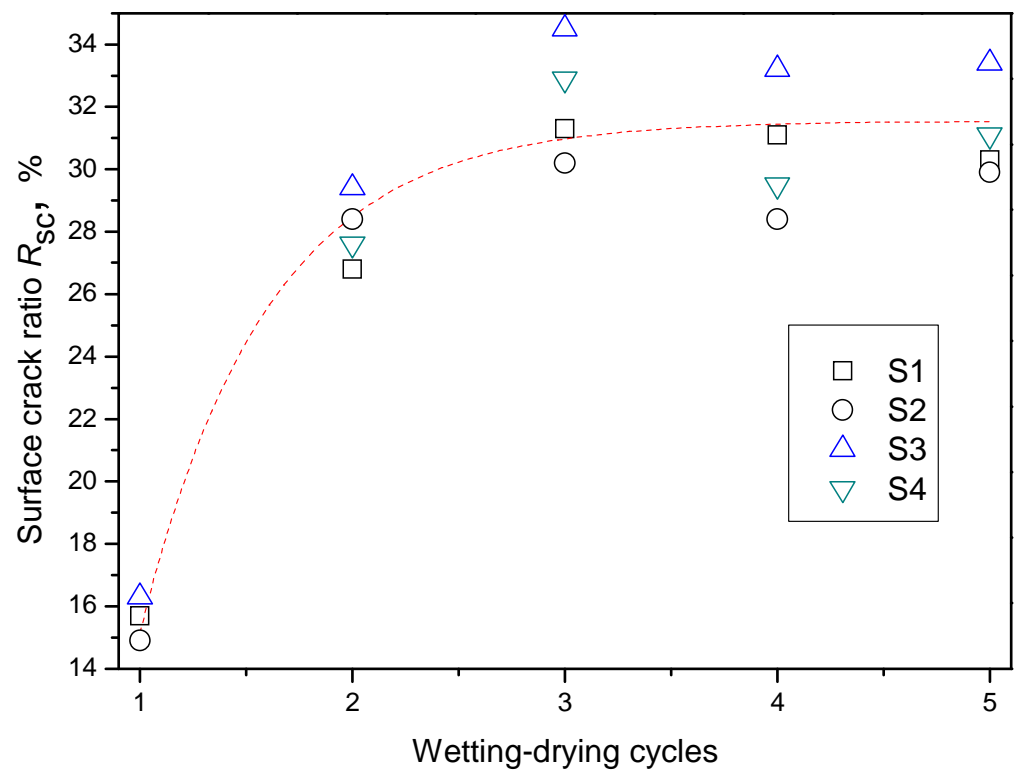

40 


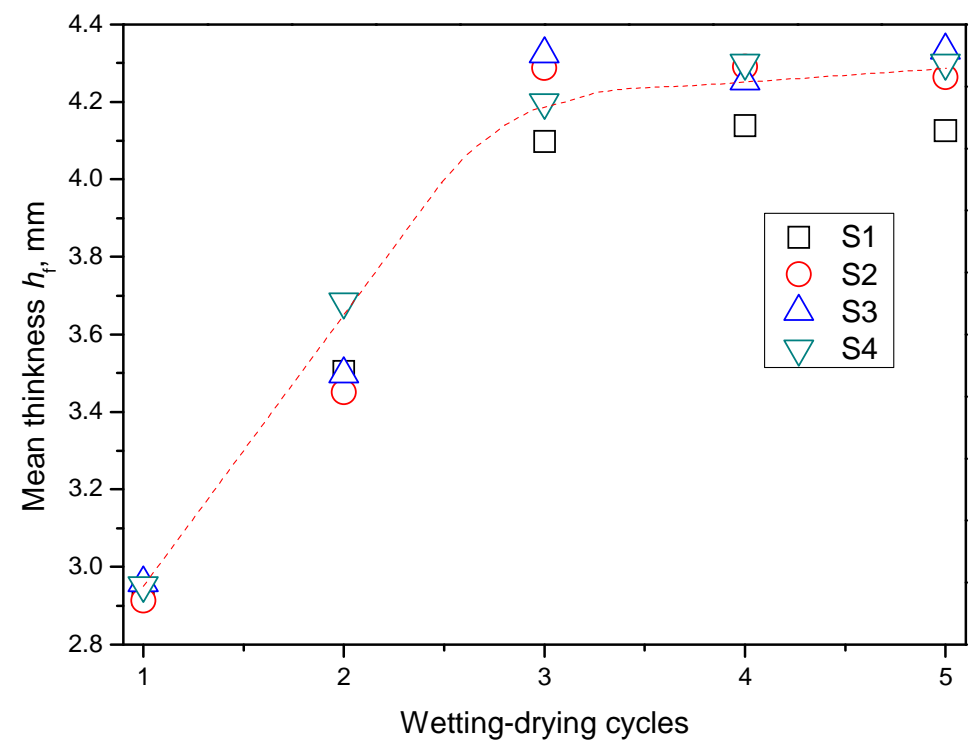

Fig. 7 Mean thickness $h_{\mathrm{f}}$ of specimen layer after each W-D cycle

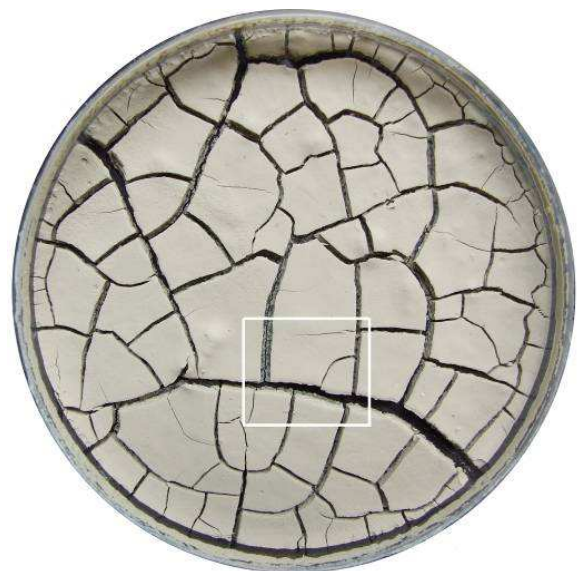

(a) After the first W-D cycle

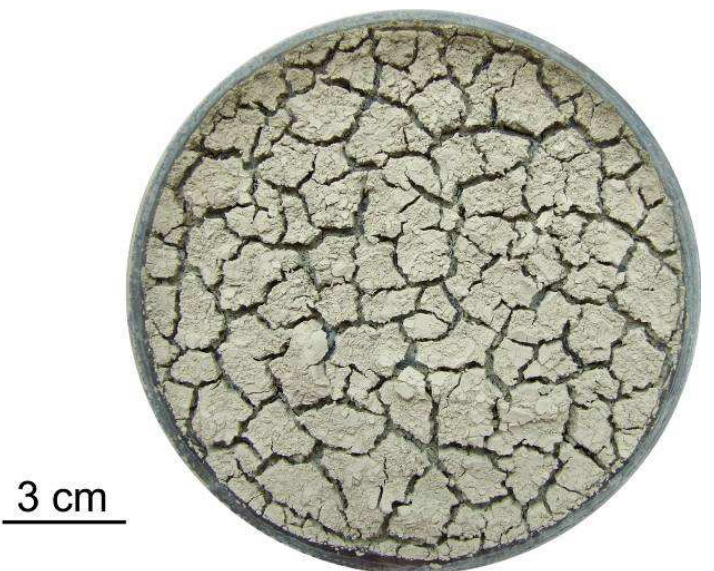

(b) After the second W-D cycle

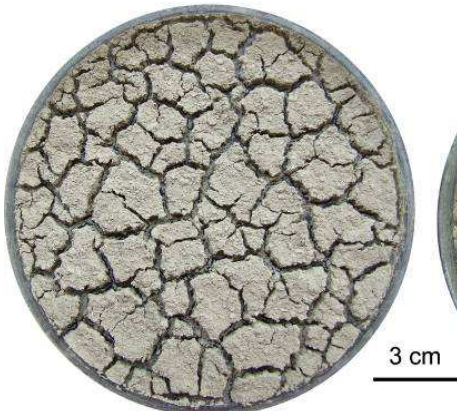

(c) After the third W-D cycle

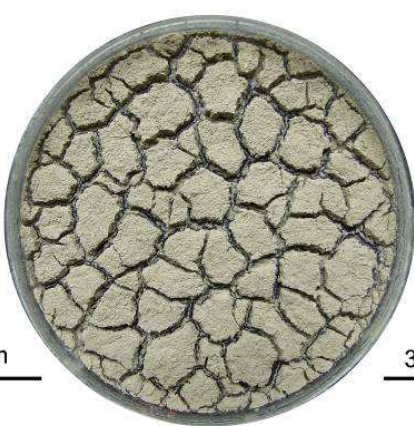

(d) After the fourth W-D cycle

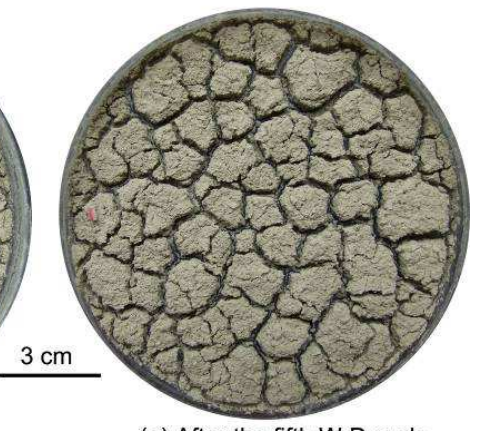

(e) After the fifth W-D cycle

Fig. 8 Typical desiccation crack patterns after each W-D cycle (pictures were taken from the same specimen) 


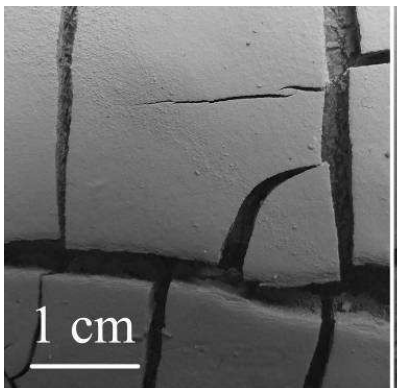

(a) 0 min

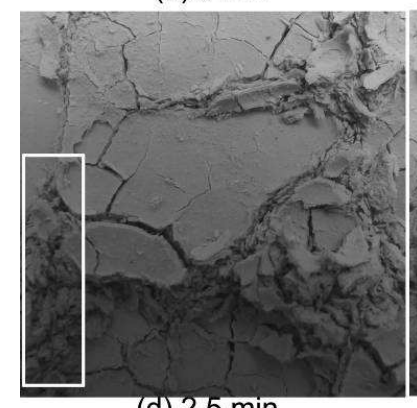

(d) $2.5 \mathrm{~min}$

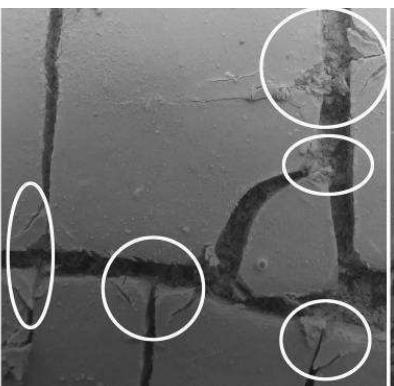

(b) $0.5 \mathrm{~min}$

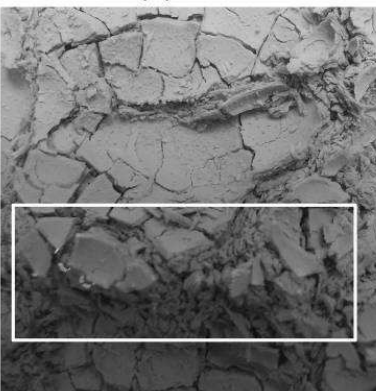

(e) $8 \mathrm{~min}$

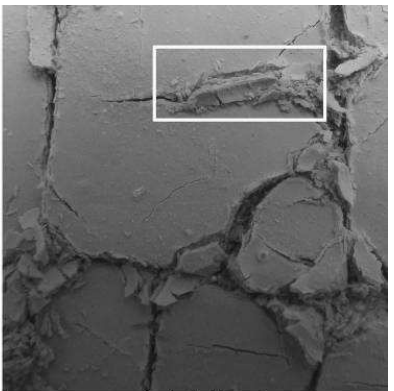

(c) $1.5 \mathrm{~min}$

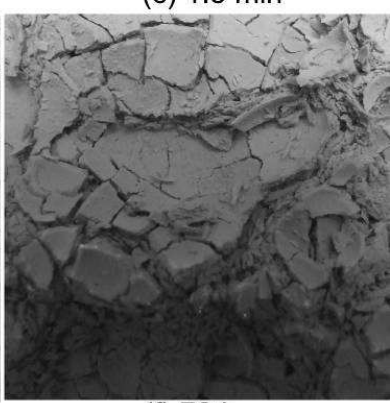

(f) $72 \mathrm{~h}$

Fig. 9 Evolution of crack pattern during the second wetting

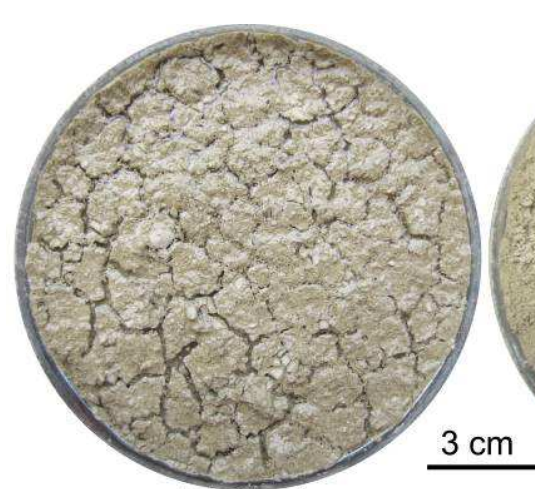

path

(a) $1 \mathrm{~min}$

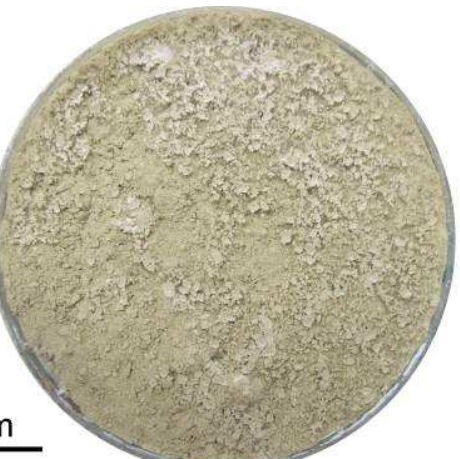

(b) $1.5 \mathrm{~min}$

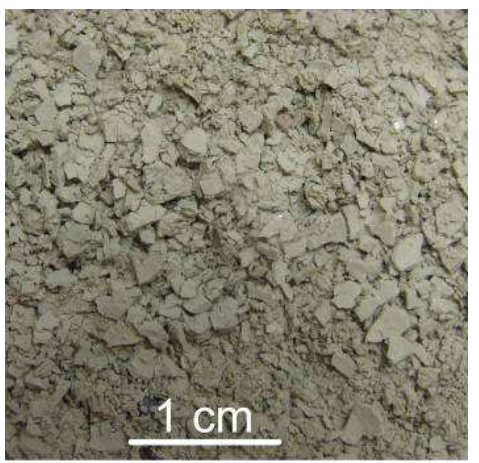

(c) $72 \mathrm{~h}$

Fig. 10 Evolution of surface cracks during the third wetting path 